\title{
Helicobacter pylori infection and hyperemesis gravidarum: a prospective pilot study in India
}

\begin{abstract}
Akhila M. V.*, Padmasri R.
Department of Obstetrics and Gynecology, Sapthagiri Institute of Medical Sciences and Research Centre, Bangalore, Karnataka, India

Received: 11 June 2019

Accepted: 17 June 2019

*Correspondence:

Dr. Akhila M. V.,

E-mail: akhilamv89@gmail.com

Copyright: (C) the author(s), publisher and licensee Medip Academy. This is an open-access article distributed under the terms of the Creative Commons Attribution Non-Commercial License, which permits unrestricted non-commercial use, distribution, and reproduction in any medium, provided the original work is properly cited.
\end{abstract}

\begin{abstract}
Background: About $80 \%$ of all pregnant women experience some form of nausea and vomiting during their pregnancy. Hyperemesis gravidarum, the commonest indication for admission to hospital in the first half of pregnancy affects approximately $0.3 \%-2.0 \%$ of pregnancies. Helicobacter pylori infection has been implicated in the cause of nausea and occasional vomiting in early pregnancy. The objectives of this study are to determine the proportion of $H$. pylori seropositivity among women with hyperemesis gravidarum (HG) and determine its relation with socio-economic status.

Methods: This was a prospective study conducted in a tertiary hospital in Bangalore among 60 pregnant women with HG for a period of 12 months. Venous blood samples were obtained and serum IgG for $H$. pylori was measured using enzyme-linked immunosorbant assay (ELISA). Details regarding socioeconomic status, recurrence of symptoms and severity were noted.

Results: The proportion of $H$. pylori seropositivity among pregnant women with hyperemesis in our study was $70 \%$. There was a significant increase in severity and recurrence of vomiting among seropositive cases. Women belonging to rural areas had 1.17 times the risk of infection compared to women with urban area. We also found women belonging to the lower socioeconomic status had 0.52 times more risk to develop Helicobacter pylori infection.

Conclusions: This study suggests that $H$. pylori is an independent risk factor for vomiting in pregnancy. Effective treatment and eradication of $\mathrm{H}$ pylori infection may help reduce severity and recurrence of vomiting among positive cases thus reducing its adverse consequences.
\end{abstract}

Keywords: Hyperemesis gravidarum, H. pylori, Pregnancy, Seropositivity, Socioeconomic status, Vomiting

\section{INTRODUCTION}

Nausea and vomiting are common symptoms seen during pregnancy in about 80 percent of all pregnant woman. ${ }^{1}$ The typical onset is between 4 and 8 weeks of gestation, with symptoms continuing until 16-18 weeks. It is generally a mild and self-limiting condition. A small percentage of pregnant women have a more profound course, with the most severe form known as hyperemesis gravidarum. Hyperemesis gravidarum affects $0.3-2 \%$ of pregnant women. ${ }^{2}$ The International Statistical Classification of Disease and Related Health Problems, Tenth Revision, defines hyperemesis gravidarum (HG) as persistent and excessive vomiting starting before the end of the $22^{\text {nd }}$ week of gestation and further subdivides the condition into mild and severe, with severe being associated with metabolic disturbances such as carbohydrate depletion, dehydration, or electrolyte imbalance. ${ }^{2}$ Hyperemesis is a diagnosis of exclusion after excluding other causes such as hyperthyroidism, 
underlying chronic illness, psychological and gastrointestinal disorders. ${ }^{3} \mathrm{HG}$ is one of the commonest indication for admission to hospital in the first half of pregnancy secondary to abortions. The condition affects both the physical and psychological profile of the woman as documented in many studies. The prevalence is more among primigravidas, multiple pregnancy, molar pregnancy, obese patients and patients with a history of nausea and vomiting in the previous pregnancy and positive family history. One of the recently recognised etiological factors for hyperemesis is $\mathrm{H}$ pylori infection. The infection is acquired by feco-oral route. $H$. pylori is a microaerophilic helical-shaped Gram negative bacterium with 4-6 flagella. It can transform from a helical to a coccoid form, which contributes toward its survival and the epidemiology of the bacterium. The bacterium colonizes the superficial mucus gel layer in the stomach and produces large amounts of ammonia, which is toxic to the epithelial cells. ${ }^{4}$ The mechanism has been theoretically explained by a sub-clinical $H$. pylori infection as a result of changes in steroid hormone levels and gastric $\mathrm{pH}$ in pregnancy. Also, some case reports have suggested that eradication of $H$. pylori infection ameliorates clinical $\mathrm{HG}^{5}$

The infection in adults is usually chronic and may not heal without specific therapy. It is more common in the developing countries compared to western countries. ${ }^{1}$ Some of the diseases causes by $\mathrm{H}$ pylori are acute gastritis peptic ulcer, chronic gastritis and adenocarcinoma stomach. The prevalence of $H$. pylori infection is known to be strongly correlated with low socioeconomic conditions and poor sanitation. ${ }^{4}$ The prevalence varies with socioeconomic status, geographic area and type of diagnostic test used. HG has been reported to be associated with an increased risk for adverse pregnancy outcomes such as low birth weight, preterm birth, and small-for-gestational age infants. ${ }^{6} \mathrm{HG}$ can be extremely debilitating for women and if inadequately treated can cause significant morbidities, including malnutrition and electrolyte imbalances, thrombosis, Wernicke's encephalopathy, depressive illness, and poor pregnancy outcomes such as prematurity and small-for-gestational-age foetuses. ${ }^{1}$

Serologic detection of $H$. pylori in patients with hyperemesis gravidarum is a non-invasive technique with high sensitivity and specificity to predict a $H$. pylori infection. ${ }^{4}$ Due to this non-invasive diagnostic method, it is possible to detect $H$. pylori infection in pregnant women. Several reports have found a significant association. $^{7-11}$ A European study showed presence of Helicobacter pylori infection in more than $90 \%$ of women with hyperemesis gravidarum have $H$. pylori infection. ${ }^{12}$ Most studies have been conducted in western countries. This is a pilot study conducted in India to detect the association between $H$. pylori infection and hyperemesis gravidarum among Indian women in a tertiary care hospital. The aims and objectives of this study are to determine the proportion of $\mathrm{H}$ pylori infection among women with hyperemesis gravidarum. to study the relation between $H$. pylori infection and socioeconomic status.

\section{METHODS}

This was a prospective study conducted in the department of Obstetrics and Gynecology. Patients with vomiting associated with pregnancy that fit into the inclusion criteria were enrolled in the study. Details regarding age, occupation, education status, socioeconomic status, housing type were gathered. Next, detailed history about vomiting, regarding the gestational age at onset, vomiting frequency, duration of vomiting, recurrence and family history were asked. Venous blood sample for Helicobacter pylori IgG antibody were obtained at the first visit and measured using enzyme-linked immunosorbant assay (ELISA). Based on the test results, the relation between $\mathrm{H}$ Pylori infection and severity was then assessed along with possible association of the infection with socioeconomic status of the patient.

\section{Inclusion criteria}

- Pregnant woman between 6 weeks and 22 weeks period of gestation with vomiting (more than 3 times a day), weight loss (more than $3 \mathrm{~kg}$ or $5 \%$ of body weight), and ketonuria.

\section{Exclusion criteria}

- Medical cause of vomiting

- Liver disorder

- Renal disorder

- Urinary tract infection

- Neurological causes of vomiting

- Surgical causes of vomiting

- Cholecystitis

- Pancreatitis

- Appendicitis

- Pregnancy beyond 22 weeks period of gestation

- Hyperemesis secondary to multiple pregnancy

- Hyperemesis secondary to trophoblastic disease.

\section{RESULTS}

This was a prospective pilot study conducted in the department of Obstetrics and Gynecology in a tertiary hospital in Bangalore. Sixty cases of hyperemesis gravidarum were studied. The results of our study are as follows. The mean age of women in our study was $24.5 \pm 3.48$ SD years. Majority of the women $(n=31,52 \%)$ were primigravidas followed by 29 multigravidas. Mean gestational age at onset was $8.97 \pm 2.38$ SD weeks.

Mean duration of symptom duration was 2.05 \pm 1.11 SD weeks. Women with less than 12 years education were 35 and women with more than 12 years of education were 25. These details are shown in Table 1. 
Table 1: Characteristics of cases.

\begin{tabular}{|ll|}
\hline Characteristic & Number \\
\hline Mean age (years) & $24.5 \pm 3.48 \mathrm{SD}$ \\
\hline Primigravida & 31 \\
\hline Multigravida & 28 \\
\hline Education & \\
\hline$<12$ years & 35 \\
\hline$>12$ years & 25 \\
\hline $\begin{array}{l}\text { Gestational age at onset of vomiting } \\
\text { (weeks) }\end{array}$ & $8.97 \pm 2.38 \mathrm{SD}$ \\
\hline $\begin{array}{l}\text { Duration of vomiting } \\
\text { (weeks) }\end{array}$ & $2.05 \pm 1.11 \mathrm{SD}$ \\
\hline
\end{tabular}

In our study, among the 60 cases of hyperemesis, 42 cases $(70 \%)$ tested positive for Serum Ig G H. pylori antibody and 18 cases $(30 \%)$ tested negative for the same. Thus majority (nearly $2 / 3^{\text {rd }}$ cases) had associated infection (Table 2).

Table 2: Serum IgG $H$. pylori test results.

\begin{tabular}{|ll|}
\hline Cases & pylori positive \\
\hline 42 & 18 \\
\hline
\end{tabular}

Table 3: Severity of symptoms.

\begin{tabular}{|lll|}
\hline $\begin{array}{l}\text { Frequency of } \\
\text { vomiting per day }\end{array}$ & H.pylori & H. pylori \\
positive & negative \\
\hline $1-2$ & 0 & 0 \\
\hline $3-4$ & 0 & 4 \\
\hline 5 & 6 & 7 \\
\hline$>5$ & 36 & 7 \\
\hline
\end{tabular}

Table 3 describes the severity of vomiting among the $\mathrm{H}$ pylori positive and negative cases. Vomiting severity was more among cases with $H$. pylori infection (36 cases) compared to only 7 cases among those negative for $\mathrm{H}$ pylori infection with a $\mathrm{p}$ value of 0.001 which is significant. This indicates infection could be a factor causing increased severity.

Table 4: Recurrence of vomiting in same pregnancy.

\begin{tabular}{|ll|}
\hline H. pylori positive cases & H. pylori negative cases \\
\hline 19 & 2 \\
\hline
\end{tabular}

Vomiting recurrence is also more among the cases positive for $\mathrm{H}$ pylori infection (19 cases) compared to 2 cases amongst women negative for infection. This was found to be statistically significant (Table 4).

Table 5 describes the association of a positive family history among cases of hyperemesis. No significant association was found between positive family history and $H$. pylori seropositivity.
Table 5: Family history and seropositivity.

\begin{tabular}{|ll|}
\hline H. pylori seropositivity & Positive family history \\
\hline Positive & 22 \\
\hline Negative & 20 \\
\hline
\end{tabular}

Table 6: Type of housing.

\begin{tabular}{|llll|}
\hline $\begin{array}{l}\text { Housing } \\
\text { type }\end{array}$ & $\begin{array}{l}\text { Number of } \\
\text { cases }\end{array}$ & $\begin{array}{l}\text { H. pylori } \\
\text { positive }\end{array}$ & $\begin{array}{l}\text { H.pylori } \\
\text { negative }\end{array}$ \\
\hline Urban & 25 & 18 & 7 \\
\hline Rural & 35 & 24 & 11 \\
\hline
\end{tabular}

Sociodemographic factors like housing, socioeconomic status are described next few tables.

Table 6 describes housing type. There were 25 women from urban setup and 35 women from rural setup. Among the women positive for infection, 24 belonged to rural and 18 belonged to the urban setup with an odds ratio of 1.179 CI (0.382-3.64). Thus the risk of developing infection is 1.17 times more among the women in rural areas compared to urban areas.

Table 7: Distribution of socioeconomic status.

\begin{tabular}{|llll|}
\hline SE status & Number & $\begin{array}{l}\text { H. pylori } \\
\text { positive }\end{array}$ & $\begin{array}{l}\text { H. pylori } \\
\text { negative }\end{array}$ \\
\hline Lower & 53 & 38 & 15 \\
\hline Middle & 7 & 4 & 3 \\
\hline
\end{tabular}

Table 7 shows the distribution of socioeconomic status in the study. $90.5 \%(n=38)$ of women with seropositivity belonged to the lower socioeconomic status compared to $9.5 \%(n=4)$ among women with improved socioeconomic status with an odds ratio of 0.52 CI (0.105-2.638).

\section{DISCUSSION}

Hyperemesis gravidarum has a multifactorial aetiology with many risk factors. Young age, primigravidas, positive family history, ethnicity, socioeconomic status and smoking are some of the risk factors. ${ }^{2}$ In our study, there was no statistical differences between seropositive and negative cases with regards age, gravidity and duration of symptoms as also see in other studies. ${ }^{4,8}$ This may due to the fact that gastrointestinal symptoms during pregnancy are more common in all primigravida women, in younger and less educated women. Many studies are being conducted across the globe studying the association of $\mathrm{H}$ pylori as an etiological factor of HG. ${ }^{13,14}$ The results have been mixed with a few studies showing strong association and a few showing insignificant association. Ours is a pilot study conducted in the Indian scenario to evaluate the same. Our study showed high incidence $(70 \%)$ of $\mathrm{H}$ pylori seropositivity among pregnant women with HG. This is similar to others studies. $3,4,6,13,15-17$ 
Venkatanarayanan $\mathrm{N}$ et al, conducted a meta analysis study on 38 cross sectional studies in 2018 and found a significant association of $\mathrm{H}$ pylori infection with $\mathrm{HG}{ }^{15}$ Similarly, Shaban et al16 found a significant association among 50 cases in his study. Elmahdy et al17 in his study found a prevalence of $75 \% \mathrm{H}$ pylori seropositivity among women with Hyperemesis. There are multiple theories explaining the mechanism. Firstly, due to elevated steroid and human chorionic gonadotropin (HCG) levels in early pregnancy, fluid retention and altered altered intracellular and extracellular volume occurs causing chance in gastric pH. Secondly, emotional liability during pregnancy due to the high hormone levels, might increase women's susceptibility to infection caused by altered cell-mediated immunity. ${ }^{13}$

H. pylori infection is transmitted through the feco-oral route and lower socioeconomic status is one of the risk factors to develop infection. Overcrowding, lack of access to safe drinking water and poor hygiene may all play a role in increasing infection rates. In our study, among the $\mathrm{H}$ pylori seropositive pregnant women with $\mathrm{HG}$, women belonging to rural housing setup had 1.17 times the risk of infection compared to women with urban background with an odds ratio of 1.179 , CI $(0.382$ 3.64). We also found women belonging to the lower socioeconomic status had 0.52 times more risk to develop $\mathrm{H}$ pylori infection with an odds ratio of $0.52 \mathrm{CI}(0.10-$ 2.6). This has also been studies in other similar studies. ${ }^{14,18}$ There was no significant difference association with education status, occupation and seropositivity.

Infection with $H$. pylori during pregnancy is associated with adverse fetal outcome such as low birth weight, preterm birth, and small-for-gestational age infants. $\mathrm{H}$ pylori infection also causes significant morbidity in the mother. Our study showed a significant association between $\mathrm{H}$ pylori infection and vomiting severity as seen in the results. Seropositive cases compared to only 7 seronegative cases showed vomiting more than 5 times a day. This finding has also been seen in other studies. ${ }^{6,19}$

Authors also found an increase in the recurrence of vomiting symptoms during the same pregnancy after temporary remission. This resulted to multiple hospital admissions in short intervals among infected women with HG. The difference amongst the seropositive cases and seronegative cases was statistically significant.

Although there was increased severity and recurrence of vomiting, we could not demonstrate a positive correlation between gestational age at onset or duration of symptoms among the seropositive cases. The reason for this could be that there are other factors causing vomiting during pregnancy apart from infection. ${ }^{4,6}$

The limitation of the study was small sample size and lack of control group to strengthen the association of infection with symptoms and outcome of HG.

\section{CONCLUSION}

According to our study, there is a high proportion of $\mathrm{H}$ pylori seropositivity among women with Hyperemesis gravidarum. Infection seems to significantly contribute to the severity and recurrence of vomiting symptoms. Low socioeconomic status is associated with greater risk for infection. More research on its effect on adverse pregnancy outcome and effect of treatment on the pregnancy outcome with a larger sample size and similar population groups needs to be conducted in the near future.

\section{ACKNOWLEDGMENTS}

Authors would like to thank Rajiv Gandhi University of Health sciences, Sapthagiri Institute of Medical Sciences and Research Centre, our Principal, the microbiology department, the accounts and audit departments.

Funding: Funded by Rajiv Gandhi University of Health Sciences, Bangalore, Karnataka, India

Conflict of interest: None declared

Ethical approval: The study was approved by the Institutional Ethics Committee

\section{REFERENCES}

1. Shaban MM, Kandil HO, Elshafei AH. Helicobacter pylori seropositivity in patients with hyperemesis gravidarum. Am J Med Sci. 2014;347(2):101.

2. McCarthy FP, ELutomski J, Greene RA. Hyperemesis gravidarum: current perspectives. Int $\mathbf{J}$ Women's Heal. 2014;6:720.

3. Cunningham, Gary F. Williams Obstetrics. 24 ${ }^{\text {th }}$ edition. New York: McGraw-Hill Education; 2014: 1070-1072.

4. Nasr AA, Aboulfoutouh I, Nada A, Younan MA, Saed M, El-Khayat W. H. pylori infection and hyperemesis gravidarum. Evidence Based Women's Health J. 2012;2:100-3.

5. Sharamif SAH, Mansour-Ghanaei F, Fallah SSMS. $H$. pylori seropositivity and hyperemesis gravidarum. Med Sci Monit. 2003;9(1):CR12-15.

6. Grooten IJ, Den Hollander WJ, Roseboom TJ, Kuipers EJ, Jaddoe VW, Gaillard R, et al. Helicobacter pylori infection: a predictor of vomiting severity in pregnancy and adverse birth outcome. Am J Obstet Gynecol. 2017;216:512.e1-9.

7. Hayakawa S, Nakajima N, Karasaki -Suzuki M, Yoshinaga H, Arakawa Y, Satoh K, et al. Frequent presence of Helicobacter pylori genome in the saliva of patients with hyperemesis gravidarum. Am J Perinatol. 2000;17:243-7.

8. Ozcimen EE, Uckuyu A, Ustuner I, Yanik FM, Kulaksizoglu S, Oktem M, et al. Helicobacter pylori positivity in patients with hyperemesis gravidarum. Gynecol Obstet Reprod Med. 2006;12:165-8.

9. Erdem A, Arslan M, Erdem M, Yildirim G, Himmetoglu O. Detection of Helicobacter pylori 
seropositivity in hyperemesis gravidarum and correlation with symptoms. Am J Perinatol. 2002; 19:87-92.

10. Kazerooni T, Taallom M, Ghaderi AA. Helicobacter pylori seropositivity in patients with Hyperemesis gravidarum. Int J Gynaecol Obstet. 2002;79:217-20.

11. Bagis T, Gumurdulu Y, Kayaselcuk F, Yilmaz ES, Killicadag E, Tarim E. Endoscopy in Hyperemesis gravidarum and Helicobacter pylori infection. Int $\mathrm{J}$ Gynaecol Obstet. 2002;79:105-9.

12. Karaca C, Guler N, Yazar A, Camlica H, Demir K, Yildirim G. Is lower socioeconomic status a risk factor for Helicobacter pylori infection in pregnant women with hyperemesis gravidarum?. Turk J Gastroenterol. 2004;15:86-9.

13. Li L, Li L, Zhou X, Xiao S, Gu H, Zhang G. Helicobacter pylori infection is associated with an increased risk of hyperemesis gravidarum:a metaanalysis. Gastroenterol Res Pract. 2015;278905.

14. Niemeijer MN, Grooten IJ, Vos N. Diagnostic markers for hyperemesis gravidarum: a systematic review and metaanalysis. Am J Obstet Gynecol. 2014;211:150.e1-15.

15. Ng QX, Venkatanarayanan N, De Deyn MLZQ, Ho CYX, Mo Y, Yeo WS. A meta-analysis of the association between Helicobacter pylori (H. pylori) infection and hyperemesis gravidarum. 2018;23(1).

16. Shaban MM, Kandil HO, Elshafei AH. Helicobacter pylori seropositivity in patients with hyperemesis gravidarum. Am J Med Sci. 2014;347(2):101-5.

17. Sameh SS, Elmahdy M, Elmarsafawy A, Elkafash D, Azza E. Helicobacter pylori Infection in Cases of Hyperemesisgravidarum; Updates. J Gynecol Women's Health. 2017;4(4).

18. Smith S, Jolaiya T, Fowora M. Pia P, Favour N, Moses B, et al. Clinical and socio- demographic risk factors for acquisition of Helicobacter pylori infection in Nigeria. Asian Pac J Cancer Prev. 2018;19(7):1851-7.

19. Shirin H, Sadan O, Shevah O, Bruck R, Boaz M, Moss SF, et al. Positive serology for Helicobacter pylori and vomiting in the pregnancy. Arch Gynecol Obestet. 2004;270:10-4.

Cite this article as: Akhila MV, Padmasri R.

Helicobacter pylori infection and hyperemesis gravidarum: a prospective pilot study in India. Int $\mathbf{J}$ Reprod Contracept Obstet Gynecol 2019;8:2856-60. 